\title{
Evaluation of spike protein antigens for SARS-CoV-2 serology
}

\author{
Suraj Jagtap ${ }^{\mathrm{a}, 1}$, Ratnasri $\mathrm{K}^{\mathrm{b}, 1}$, Priyanka Valloly ${ }^{\mathrm{a}, 1}$, Rakhi Sharma ${ }^{\mathrm{a}}$, Satyaghosh Maurya ${ }^{\mathrm{a}}$, \\ Anushree Gaigore ${ }^{a}$, Chitra Ardhya ${ }^{c}$, Dayananda S. Biligi ${ }^{c}$, Bapu Koundinya Desiraju ${ }^{\mathrm{d}}$, \\ Uma Chandra Mouli Natchu ${ }^{\mathrm{e}}$, Deepak Kumar Saini ${ }^{\mathrm{b}, \mathrm{f}}$, Rahul Roy ${ }^{\mathrm{a}, \mathrm{b}, *}$ \\ ${ }^{a}$ Department of Chemical Engineering, Indian Institute of Science, Bangalore, 560012, India \\ ${ }^{\mathrm{b}}$ Centre for BioSystems Science and Engineering, Indian Institute of Science, Bangalore, 560012, India \\ ${ }^{\mathrm{c}}$ Department of Pathology, Bangalore Medical College and Research Institute, Bangalore, 560002, India \\ d Translational Health Science and Technology Institute, NCR Biotech Science Cluster, Faridabad, 121001, India \\ ${ }^{\mathrm{e}}$ Division of Infectious Diseases, St. John's Research Institute, Bangalore, 560034, India \\ ${ }^{\mathrm{f}}$ Department of Molecular Reproduction, Development and Genetics, Indian Institute of Science, Bangalore, 560012, India
}

\section{A R T I C L E I N F O}

\section{Keywords:}

SARS-CoV-2

Serology

Spike trimer ELISA

\begin{abstract}
A B S T R A C T
Background: Spike protein domains are being used in various serology-based assays to detect prior exposure to SARS-CoV-2 virus. However, there has been limited comparison of antibody titers against various spike protein antigens among COVID-19 infected patients.

Methods: We compared four spike proteins (RBD, S1, S2 and a stabilized spike trimer (ST)) representing commonly used antigens for their reactivity to human IgG antibodies using indirect ELISA in serum from COVID19 patients and pre-2020 samples. ST ELISA was also compared against the EUROIMMUN IgG ELISA test. Further, we estimated time appropriate IgG and IgA seropositivity rates in COVID-19 patients using a panel of sera samples collected longitudinally from the day of onset of symptoms (DOS).

Results: Among the four spike antigens tested, the ST demonstrated the highest sensitivity (86.2\%; $95 \%$ CI: 77.8-91.7 \%), while all four antigens showed high specificity to COVID-19 sera (94.7-96.8\%). 13.8\% (13/94) of the samples did not show seroconversion in any of the four antigen-based assays. In a double-blinded head-tohead comparison, ST based IgG ELISA displayed a better sensitivity (87.5\%, $95 \%$ CI: 76.4-93.8 \%) than the EUROIMMUN IgG ELISA (67.9 \%, 95 \% CI: 54.8-78.6 \%). Further, in ST-based assays, we found $48 \%$ and $50 \%$ seroconversion in the first six days (from DOS) for IgG and IgA antibodies, respectively, which increased to $84 \%$ ( $\operatorname{IgG})$ and $85 \%$ (IgA) for samples collected $\geq 22$ days from DOS.

Conclusions: Comparison of spike antigens demonstrates that spike trimer protein is a superior option as an ELISA antigen for COVID-19 serology.
\end{abstract}

\section{Introduction}

COVID-19 pandemic caused by the Severe Acute Respiratory Syndrome Coronavirus 2 (SARS-CoV-2) has already crossed 178 million detected cases and over 3.8 million deaths worldwide till date (Dong et al., 2020). As the pandemic continues, we need accurate and sensitive tests to assess the prevalence, disease burden and the level of population immunity against the virus. With the introduction of multiple vaccines and several ongoing vaccine trials, identifying prior exposure or immunogenicity of the vaccine in individuals becomes critical to the development of vaccination and public health strategies.
Nucleic acid-based tests that detect viral RNA are widely used to diagnose active infection in SARS-CoV-2 infected individuals (Mathuria et al., 2020; Sethuraman et al., 2020). In contrast, immunological tests like serological assays detect the level of antibody response in humans to the infection in symptomatic as well as the large fraction of asymptomatic infections (Galipeau et al., 2020; Long et al., 2020; Milani et al., 2020; Oved et al., 2020). Immuno-assays detect antigen-specific IgA, IgM and IgG immunoglobulins (antibodies) from body fluids like serum or plasma. Viral antigen-specific antibodies can be detected in SARS-CoV-2 exposed individuals within 5-12 days post-onset of symptoms (POS) for IgM and IgA antibodies and 14 days for IgG antibodies

\footnotetext{
* Corresponding author at: Department of Chemical Engineering, Indian Institute of Science, Bangalore, 560012, India.

E-mail address: rahulroy@iisc.ac.in (R. Roy).

1 Contributed equally to this work.
} 
(Guo et al., 2020; Zhao et al., 2020). IgG antibodies are long-lived, detectable for up to 12 months, making them recent and long-term markers of exposure to SARS-CoV-2 compared to short-lived IgA and IgM (Dan et al., 2021; Laing et al., 2021).

Serological assays with nucleocapsid or spike (S) protein of SARS$\mathrm{CoV}-2$ as capturing antigen have been widely developed and reported, as these antigens are highly immunogenic (Jiang et al., 2020; Premkumar et al., 2020). Nucleocapsid based ELISA assays have shown to be less specific, contributing to false positive results (Katz et al., 2020; Yamaoka et al., 2020). The spike protein decorates the exterior of SARS-CoV-2 virus that helps the virus to bind to the ACE2 receptors on the host cell membrane, promotes fusion of the viral membrane with the host cell and thereby enables the entry of the viral genome into the host cell cytoplasm (Huang et al., 2020; Shang et al., 2020b, 2020a). Anti-spike antibodies also demonstrate high virus neutralization efficacy (Suthar et al., 2020; Wajnberg et al., 2020). The spike glycoprotein is a clove-shaped trimeric protein with each unit consisting of the S1 head and the S2 stalk. The Receptor Binding Domain (RBD) of the S1 head is responsible for binding to the ACE2 receptor on the cellular membrane, initiating cell entry (Huang et al., 2020; Walls et al., 2020). Due to the large size of the S protein and its highly hydrophobic S2 region, traditional mammalian expression systems produce low levels of recombinant protein. Additionally, absence of post-translational modifications in bacterial expression systems precludes the expression of this glycosylated protein in E. coli. Capture antigens used for serological assays should be easy to express and purify, with high yield and stability. Recently, the prefusion state of SARS-CoV-2 spike trimer (ST) protein was stabilized by the addition of 6 prolines that improved thermal stability and expression yield in mammalian cell suspension culture, making it a promising antigen for SARS-CoV-2 antibody assays (Hsieh et al., 2020).

In this study, we evaluated the ST protein as a potential capture antigen for ELISA and compared it with different subunits of $S$ protein, namely, S1, S2 and RBD to assess IgG antibody titers in SARS-CoV-2 positive and pre-pandemic sera. We also used ST protein to elucidate IgG and IgA antibody response dynamics with time-stratified samples ( $\leq 6,7-14,15-21$ and $\geq 22$ days POS). Further, we benchmarked the ST protein ELISA against an FDA approved (EUROIMMUN) serology ELISA kit.

\section{Materials and methods}

\subsection{Sample collection}

For COVID-19 samples, 1-2 ml of blood was drawn from patients who had tested positive for SARS-CoV-2 by RT-PCR test. One set of serum samples $(n=69)$ of COVID-19 patients were obtained from individuals hospitalized at Bangalore Medical College and Research Institute (BMCRI) between April-May 2020. All these samples were collected $\geq 15$ days post-onset of symptoms or RT-PCR positivity (POS/ RT). A separate set of serum samples $(n=100$; collected between MarchAugust 2020) were obtained from COVID-19 biorepository of Translational Health Science and Technology Institute, Delhi (THSTI) that were time stratified along the course of COVID-19 infection (25 samples each from day $0-6,7-14,15-21$ and $\geq 22$ days POS). For COVID-19 negative controls, serum samples collected during 2018-19 from healthy donors $(n=33)$ and dengue patients $(n=61$, Panbio dengue IgG/IgM capture ELISA kits, 01PE10/01PE20) and stored in $-80{ }^{\circ} \mathrm{C}$ were used. We also tested the control samples for Influenza A/B antibodies (Immunolab Influenza A/B IgG ELISA, ILE-IFA01/ILE-IFB01). Informed consent from patients was received as per study protocols approved by the Institute Ethics Committees of the institutes where samples were collected, and assays were performed.

\subsection{Protein expression and purification}

The plasmids for RBD (pCAGGS vector containing the human codonoptimized RBD (amino acids 319-541) SARS-CoV-2, Wuhan-Hu-1 spike glycoprotein, GenBank: MN908947; a gift from Florian Krammer, Mount Sinai, New York) and the ST protein (HexaPro; a gift from Jason McLellan, University of Texas, Austin; based on the MN908947 (aa 1-1208) with 6 proline mutations F817 P, A892 P, A899 P, A942 P, K986 P, V987 P and replacement of furin site (682-685) by 'GSAS') were purified from DH5 $\alpha$ strain of $E$. coli. The plasmids were transfected into Expi293 F cells grown using Expi293 expression medium (Thermo Fisher, A1435101). The cells were grown in an orbital shaker cell culture incubator $\left(37^{\circ} \mathrm{C}, \geq 80 \%\right.$ relative humidity, $\left.8 \% \mathrm{CO}_{2}, 130 \mathrm{rpm}\right)$. Transfection was done at a final cell density of $3 \times 10^{6}$ viable cells $/ \mathrm{mL}$ using ExpiFectamine 293 Transfection Kit (Thermo Fisher, A14525) as per instructions. Culture media were harvested after 5 days posttransfection. ST protein was purified using Gravity Flow Strep-Tactin XT resin (IBA Lifesciences, 2-5998-000), whereas RBD protein was purified by HisTrap FF Crude histidine-tagged column (GE Healthcare GE17-5247-01) on AKTA-Start FPLC system (GE Healthcare/ Cytiva) and concentrated using Centricon filter spin columns (Merck ACS505024). Average purified protein yields of $12 \mathrm{mg} / \mathrm{L}$ and $61 \mathrm{mg} / \mathrm{L}$ were achieved for ST and RBD protein respectively. Spike protein subunits S1 (Native Antigen, REC31806, GenBank: YP_009724390.1 [aa: 1-674]) and S2 (Native Antigen, REC31807, GenBank: YP_009724390.1 [aa: 685-1211]) for SARS-CoV-2 were commercially purchased. MN908947 and YP_009724390.1 amino acid sequences are same in the $\mathrm{S}$ protein region.

\subsection{Human IgG and IgA SARS-CoV-2 ELISA}

Microtiter plates (Thermo Fisher, 442,404) were coated with $50 \mu 1$ antigen at a concentration of $5 \mu \mathrm{g} / \mathrm{mL}$ in $0.1 \mathrm{M}$ sodium carbonatebicarbonate buffer ( $\mathrm{pH}$ 9.6) and incubated overnight at $4{ }^{\circ} \mathrm{C}$. Excess unbound antigen was removed by washing the wells thrice with $200 \mu \mathrm{l}$ wash buffer (0.1\% Tween 20 in PBS) using an automated plate washer (Tecan HydroFlex). After washing, $100 \mu \mathrm{l}$ of blocking buffer $(10 \mathrm{mg} / \mathrm{mL}$ BSA, $0.05 \%$ Tween 20 in PBS) was added to the wells and plates were incubated at room temperature (RT) for $1 \mathrm{~h}$ with gentle shaking, followed by washing. Serum samples $(50 \mu \mathrm{l})$ diluted 1:100 times in PBS with $1 \mathrm{mg} / \mathrm{mL}$ BSA were added to the wells. After $30 \mathrm{~min}$ of incubation at RT, plates were washed 5 times with $300 \mu \mathrm{l}$ of wash buffer. $50 \mu \mathrm{l}$ of horseradish peroxidase-conjugated goat anti-Human IgG (GeNei, HPO2) or IgA specific (Sigma-Aldrich, A0295) antibody diluted 1:3000 in PBS, $0.1 \mathrm{mg} / \mathrm{mL}$ BSA, and $0.05 \%$ Tween 20 was added to the wells and incubated at RT for $30 \mathrm{~min}$. Excess antibody-enzyme conjugate was removed by washing the wells 5 times with $300 \mu$ wash buffer. $50 \mu \mathrm{l}$ of chromogenic tetramethylbenzidine (TMB) substrate was added, and plates were incubated in the dark with constant shaking. The reaction was stopped after $10 \mathrm{~min}$ by adding $50 \mu \mathrm{l}$ of stop solution (8.5 M acetic acid and $0.5 \mathrm{M}$ sulfuric acid). Absorbance was measured at $450 \mathrm{~nm}$ using a microplate reader (Thermo Scientific Varioskan Flash). Background signal for each sample was estimated by running the same assay without any antigen coating. Corrected OD value was obtained by subtracting the background signal for each sample from its respective OD value in the presence of the antigen. The cut-off value was calculated based on the mean and standard deviation (SD) of the control samples' OD values as mean +3 SD.

Antigen concentration for ELISA was determined by titrating the antigens at different concentrations till signal saturation. The ST reactivity to SARS specific antibodies was tested with an ELISA titration of the SARS Spike specific antibody CR3022 (Native Antigen MAB12422, Supplementary Fig. 1). Diluted serum was titrated, and IgG ELISA was performed using ST with COVID-19 positive and control samples to determine the optimal sera dilution (Supplementary Fig. 2). We selected 1:100 sera dilution for performing all the ELISAs based on the high 
correlation between area under the sera dilution curves and the signal contrast between COVID-19 and control samples (Supplementary Fig. 2c-d).

Head-to-head comparison of ST ELISA and EUROIMMUN Anti-SARSCoV-2 (IgG) ELISA (S1 protein-based serology kit approved by FDA and ICMR, EI 2606-9601 G (EUROIMMUN, 2020)) was performed in a double-blind format where the experimenters were blind to the RT-PCR and seropositivity results. EUROIMMUN ELISA was performed as per the manufacturer's instructions.

\subsection{Data analysis}

All statistical analyses and visualization were done using customwritten python codes and GraphPad Prism software (v8.4.3). Unpaired two-tailed Student's $t$-test was used to compare the COVID-19 positive and negative groups. Confidence intervals were calculated using Wilson/Brown's method (Brown et al., 2001).

\section{Results}

\subsection{Comparison between different spike antigens for human IgG antibodies}

We compared four different spike protein antigens (S1, S2, RBD and ST) that represent different protein segments commonly being used to evaluate serum reactivity among SARS-CoV-2 patients (Fig. 1a). 94 COVID-19 samples collected $\geq 15$ days from DOS/RT, and 94 control samples were tested for the presence of spike-specific IgG antibodies (Fig. 1b). We noted that in-house purified RBD and ST performed better than commercially procured S1 and S2 in terms of sensitivity and intensity of the positive sample signal. ST showed the highest sensitivity (86.2 \%) followed by RBD (69.9\%), while S1 and S2 domains showed very low sensitivity (51.5\% and $50.0 \%$, respectively) (Table 1 ). 13 COVID-19 samples were found below the cut-off values for all four antigens.

Among control samples, $64.9 \%(61 / 94)$ were positive for Dengue IgG ELISA, $96.8 \%$ (91/94) for Influenza A and $97.8 \%(92 / 94)$ for Influenza B IgG antibodies. This confirmed that these control samples had other detectable virus specific antibodies. Despite this, we obtained specificity $>94.7 \%$ for all the four antigens (Table 1), suggesting low cross-reactivity of spike antigens to antibodies for these viruses.

S1, RBD and ST antigens displayed a high correlation among themselves (Pearson's correlation coefficient (PCC) $>0.75$ for all cases). S2 subunit displayed a lower correlation (PCC $0.66-0.68$ ) to others. This is likely because the structurally buried $\mathrm{S} 2$ domain in the spike protein is less accessible to the antibodies. Nevertheless, the significant correlation across all four antigens (Fig. 1c, PCC $>0.65$ ), suggests that antibody responses across all spike antigens are consistent and that they are all detectable in our ELISA platform.

ST detected higher OD values, possibly because of the larger number

Table 1

Sensitivity and specificity with $95 \%$ confidence intervals (CI) for different spike antigen-based assays.

\begin{tabular}{lll}
\hline Antigen & Sensitivity (\%) & Specificity (\%) \\
\hline S1 & $51.1(41.1-60.9)$ & $96.8(91.0-99.1)$ \\
S2 & $50.0(40.1-59.9)$ & $95.7(89.6-98.3)$ \\
RBD & $69.9(59.9-78.3)$ & $94.7(88.1-97.7)$ \\
ST & $86.2(77.8-91.7)$ & $96.8(91.0-99.1)$ \\
\hline
\end{tabular}

(a)

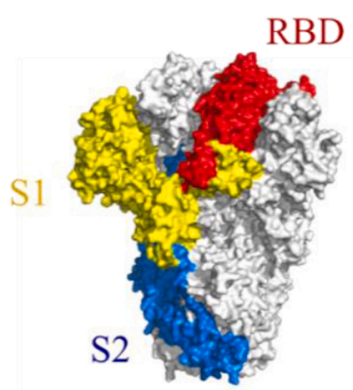

(c)

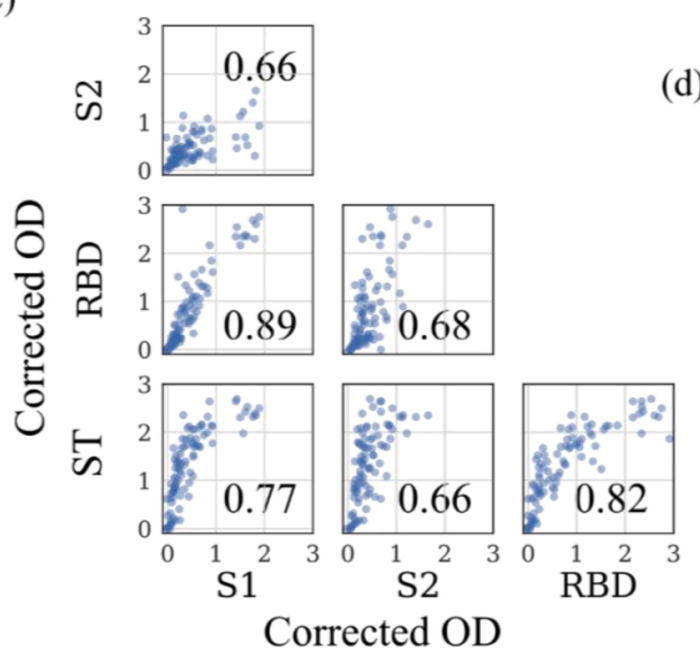

(b)

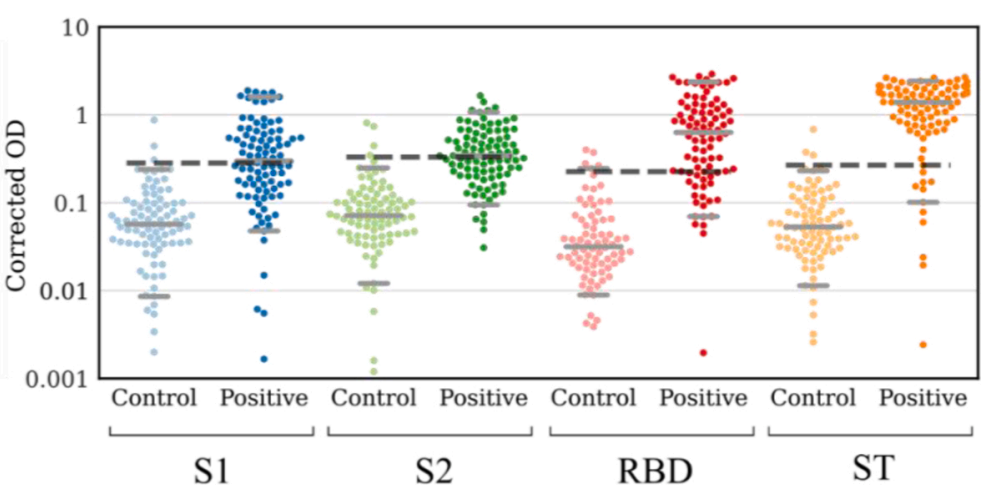

(d)

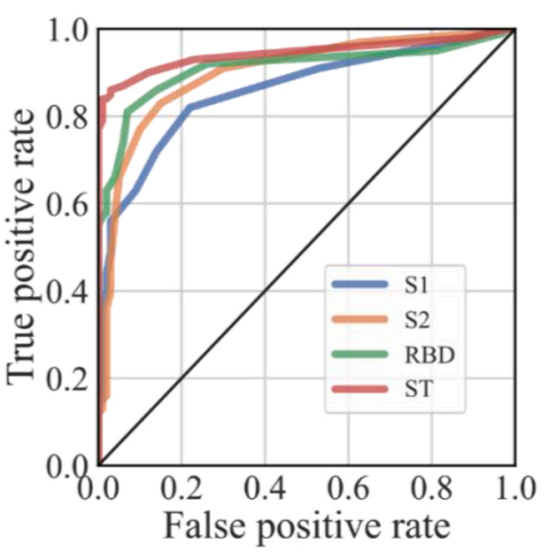

Fig. 1. Reactivity of COVID-19 positive ( $\mathrm{n}=94$ samples collected $\geq 15$ days from day of -onset of symptoms or RTPCR positivity) and control sera ( $\mathrm{n}=$ 94) to different antigens (a) Trimeric prefusion spike protein structure (PDB: 5XLR (Gui et al., 2017)) shows the antigens used in the ELISA (red: RBD, yellow and red: S1 domain, blue: S2 domain, two monomers are represented in white) (b) Corrected OD (450 nm) value for S1, S2, RBD and ST protein for each sample is represented by a point on the scatter plot. Median, 5th percentile and 95 th percentile values are shown by horizontal grey lines. Dotted lines indicate the cut-off values. (mean $+3 x$ standard deviation of corrected OD values of control samples). (c) Correlation between the four antigens. Corrected OD values for each antigen are plotted against the values for the other antigens. Pearson's correlation coefficient for each pair of antigens is shown on the scatter plots. (d) Receiver operating characteristic (ROC) curve for each antigen. 
of epitopes available on the full-length soluble trimeric protein. It also displayed the highest contrast between COVID-19 positive and control groups (Fig. 1b). Receiver operating characteristic (ROC) curves indicates that ST is the best candidate for serological testing with the highest area under the curve (Fig. 1d, area under the ROC curves S1: 0.86, S2: 0.90, RBD: 0.91, ST: 0.94). Further, when the ST-based ELISA was repeated in 93 samples (56 COVID-19 positive samples and 37 control samples) in a blind manner, we obtained highly reproducible values (PCC $=0.986$, Supplementary Fig. 3).

\subsection{Comparison with commercial IgG serology kit}

Corrected OD values obtained from ST-based ELISA and ratios obtained from EUROIMMUN test show a good correlation in a double-blind comparison (Fig. 2). However, the ST-based ELISA (87.5 \% (95 \% CI: 76.4-93.8 \%)) performed better than the EUROIMMUN IgG kit $(67.9 \%$ (95\% CI: 54.8-78.6\%)) in terms of sensitivity (for samples $\geq 15$ days from DOS/RT). Our results are comparable to values reported by the internal validation report of EUROIMMUN (61.1\% for 11-21 days from DOS and $81.1 \%$ for $>11$ days post PCR positivity (EUROIMMUN, 2020)) and lesser than those obtained by others ( $84.4 \%$ (Montesinos et al., 2020), $89.5 \%$ (van Elslande et al., 2020)). Specificity values of both methods were comparable - $94.6 \%$ (95 \% CI: 82.3-99.0\%) for ST-based ELISA and $97.3 \%$ (95 \% CI: 86.2-99.9 \%) for EUROIMMUN kit.

\subsection{Dynamics of IgG and IgA response in SARS-CoV-2 infections}

We performed ELISA assays for spike specific IgG and IgA antibodies in sera collected at different time points $(\leq 6,7-14,15-21$ and $\geq 22$ days POS) using ST protein. Median OD values of IgG and IgA response increased with time (Fig. 3a-b; IgG: 0.21, 0.69, 1.40, 1.57, IgA: 0.26, $0.49,0.77,1.06$ for the respective time intervals). Also, the proportion of patients who demonstrated seroconversion increased with time (Fig. 3c; IgG: $48.0 \%, 64.0 \%, 84.0 \%, 84.0 \%$, IgA: 50.0, 69.6, 72.7, $85.0 \%$ for the respective time intervals). In both cases, about $50 \%$ of the patients had seroconverted within 6 days from DOS. These findings are in line with previous reports that have shown median time for seroconversion based on spike specific IgG antibodies to be 14 days POS (To et al., 2020; Wölfel et al., 2020; Zhao et al., 2020). A high correlation (PCC = 0.76,

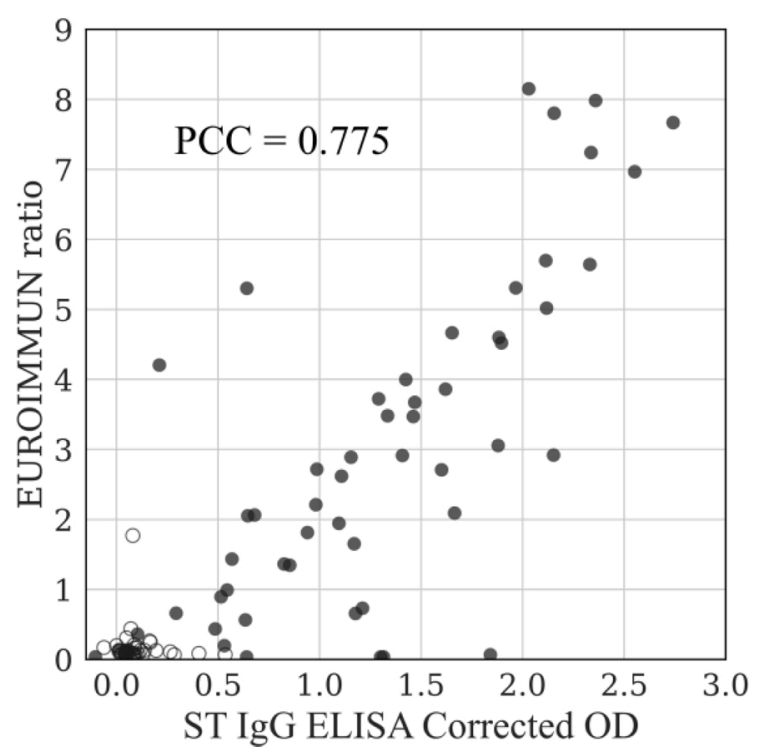

Fig. 2. Head-to-head double-blinded comparison of EUROIMMUN Anti-SARSCoV-2 ELISA (IgG) kit and ST ELISA. COVID-19 positive samples (filled circles) and control samples (empty circles) are plotted and Pearson's correlation coefficient (PCC) between the two test values is indicated for the COVID-19 positive samples.
Fig. 3d) was observed between ranks of IgG and IgA values for each sample suggesting a comparable and concomitant response to the infection.

Some individuals did not show detectable spike-specific antibodies ( $16 \%$ for IgG, $15 \%$ for IgA) even after 21 days from DOS. This could be due to asymptomatic/mild infection which has been reported to display low antibody titers (Long et al., 2020). We cannot rule-out false-positive PCR results contributing to some of these cases.

\section{Discussion}

The trimeric spike protein from SARS-CoV-2 is critical for cellular entry and is prominently displayed on the virus. Our results revealed that ST protein displayed better reactivity to COVID-19 positive sera when compared to S1, S2 and RBD spike subunit proteins consistent with the larger number of accessible antibody epitopes on ST. While we did not perform neutralization assays, previous studies have shown that the antibodies against RBD are strongly correlated with neutralization of the virus (Amanat et al., 2020; Suthar et al., 2020; Wajnberg et al., 2020). Several other regions of the Spike protein, including a region away from receptor binding site (Yuan et al., 2020), S1 domain (Hoffmann et al., 2020) and S2 domain (Duan et al., 2005; Elshabrawy et al., 2012; Xia et al., 2020) are targets of neutralizing antibodies. Therefore, a high ELISA signal against the ST protein is suggestive of higher levels of a broader spectrum of virus-neutralizing antibodies.

Purification of the trimeric spike protein (ST) from mammalian cell culture has generally been challenging compared to the smaller RBD segment (Amanat et al., 2020; Klumpp-Thomas et al., 2021). Recent development of pre-fusion stabilized spike variant (HexaPro) seems to resolve this issue (Hsieh et al., 2020). We indeed recovered $>10 \mathrm{mg} / \mathrm{L}$ ST protein consistently in our preparations. However, it was not clear if this stabilized ST protein with six proline mutations is sufficiently antigenic against COVID-19 infection induced antibodies. Our results suggests that HexaPro variant of the spike protein indeed folds and maintains the original epitopes comparable to the spike on the SARS-CoV-2 virus.

IgG and IgA antibody dynamics show seroconversion in about half of the patients within 6 days POS (also reported earlier, (Liu et al., 2020; Wölfel et al., 2020; Zhao et al., 2020)). Considering the low sensitivity of many existing rapid antigen tests (Gremmels et al., 2020; ICMR, 2020; Scohy et al., 2020), a combination of the rapid antigen detection with antibody tests can be employed to increase the detection efficiency of COVID-19 cases during early infection.

Some COVID-19 RT-PCR positive samples did not show reactivity against any of the four antigens. Several other studies have reported limited seroconversion at the time of sera collection (Brochot et al., 2020; Long et al., 2020; Staines et al., 2020). Nevertheless, highly sensitive serology assays can be critical in determining the sero-prevalence in a community as well as help in assessing the immune response/ immunogenicity of vaccines including the temporal course of antibody responses. Our results show that the antibody response in humans is consistent among the spike antigens, and the spike trimer maybe the best choice of antigen for COVID-19 serology.

\section{Author contributions}

Suraj Jagtap: Conceptualization, Methodology, Investigation, Formal Analysis, Visualization, Writing-original draft, Writing-reviewediting, Sample collection and Records. Ratnasri K: Conceptualization, Methodology, Investigation, Formal Analysis, Visualization, Writing-original draft, Writing-review-editing, Sample collection and Records. Priyanka Valloly: Conceptualization, Methodology, Investigation, Formal Analysis, Visualization, Writing-original draft, Writingreview-editing, Sample collection and Records. Rakhi Sharma: Reagent generation and Investigation. Satyaghosh Maurya: Reagent generation and Investigation. Anushree Gaigore: Reagent generation 
(a)

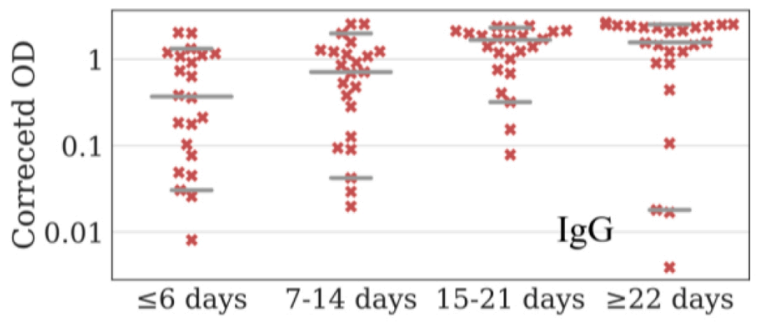

(c)

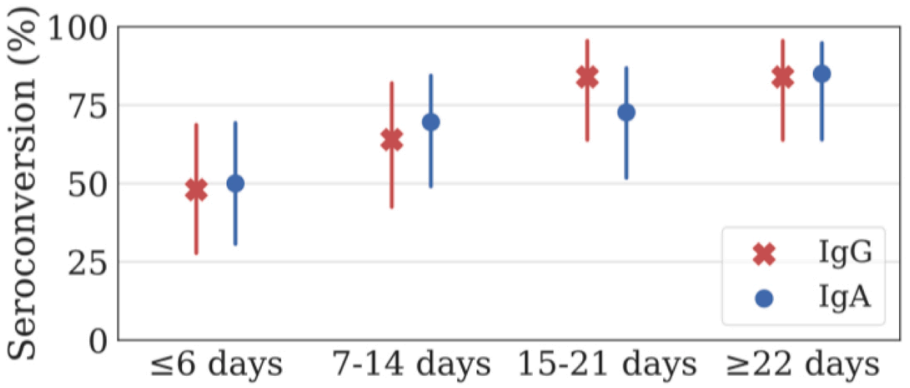

(b)

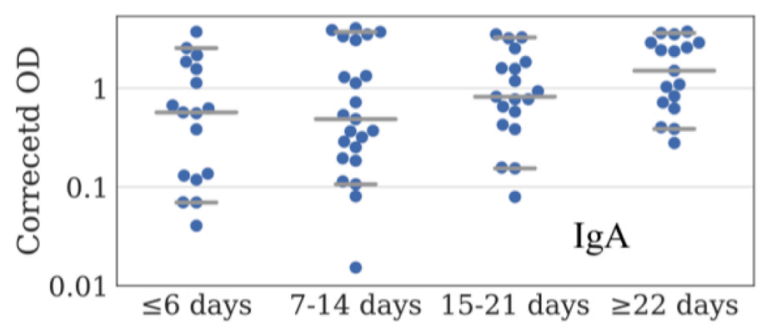

(d)

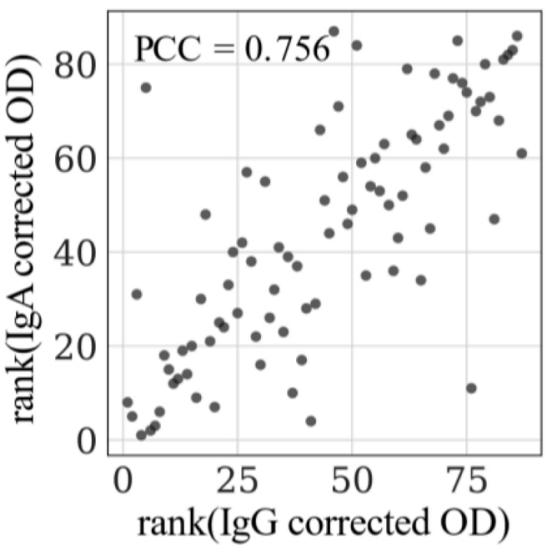

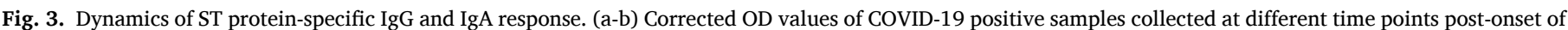

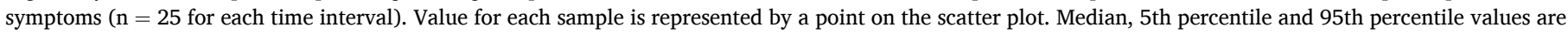

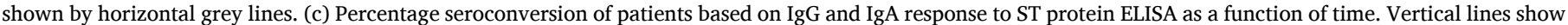
$95 \%$ confidence intervals (d) Comparison between ranks of the IgG and IgA corrected OD values.

and Investigation. Chitra Ardhya: Methodology, Sample collection and Records. Dayananda S. Biligi: Methodology, Sample collection and Records. Bapu Koundinya Desiraju: Formal Analysis. Uma Chandra Mouli Natchu: Formal Analysis and Writing-review-editing. Deepak Kumar Saini: Methodology and Writing-review-editing. Rahul Roy: Conceptualization, Methodology, Investigation, Formal Analysis, Visualization, Writing-original draft, Writing-review-editing, Sample collection and Records, Supervision.

\section{Declaration of Competing Interest}

The authors declare that there is no conflict of interest.

\section{Acknowledgements}

This research has been conducted with the contribution of NCR Biotech Science Cluster BIOREPOSITORY, DBT India consortium for COVID-19 Research and RGUHS-IISc Dengue biomarker research consortium. We thank Florian Krammer, Jason McLellan, Raghavan Varadarajan, Sameer Malladi for providing useful reagents; Sunaina Banerjee and Rohit Dutta for valuable discussions and Khantesh Agrawal for anonymizing the samples. This work was supported by the Indian Institute of Science, Biotechnology Industry Research Assistance Council and CSR funding by Capgemini India. Funding agencies had no role in the design, execution, or interpretation of the study.

\section{Appendix A. Supplementary data}

Supplementary material related to this article can be found, in the online version, at doi:https://doi.org/10.1016/j.jviromet.2021.114222.

\section{References}

Amanat, F., Stadlbauer, D., Strohmeier, S., Nguyen, T.H.O., Chromikova, V., McMahon, M., Jiang, K., Arunkumar, G.A., Jurczyszak, D., Polanco, J., BermudezGonzalez, M., Kleiner, G., Aydillo, T., Miorin, L., Fierer, D.S., Lugo, L.A., Kojic, E.M., Stoever, J., Liu, S.T.H., Cunningham-Rundles, C., Felgner, P.L., Moran, T., GarcíaSastre, A., Caplivski, D., Cheng, A.C., Kedzierska, K., Vapalahti, O., Hepojoki, J.M., Simon, V., Krammer, F., 2020. A serological assay to detect SARS-CoV-2 seroconversion in humans. Nat. Med. 26, 1033-1036. https://doi.org/10.1038/ s41591-020-0913-5.

Brochot, E., Demey, B., Touzé, A., Belouzard, S., Dubuisson, J., Schmit, J.L., Duverlie, G., Francois, C., Castelain, S., Helle, F., 2020. Anti-spike, anti-nucleocapsid and neutralizing antibodies in SARS-CoV-2 inpatients and asymptomatic individuals. Front. Microbiol. 11, 2468. https://doi.org/10.3389/fmicb.2020.584251.

Brown, L.D., Cai, T.T., das Gupta, A., 2001. Interval estimation for a binomial proportion. Stat. Sci. 16, 101-117. https://doi.org/10.1214/ss/1009213286.

Dan, J.M., Mateus, J., Kato, Y., Hastie, K.M., Yu, E.D., Faliti, C.E., Grifoni, A., Ramirez, S. I., Haupt, S., Frazier, A., Nakao, C., Rayaprolu, V., Rawlings, S.A., Peters, B., Krammer, F., Simon, V., Saphire, E.O., Smith, D.M., Weiskopf, D., Sette, A., Crotty, S., 2021. Immunological memory to SARS-CoV-2 assessed for up to 8 months after infection. Science, eabf4063. https://doi.org/10.1126/science.abf4063.

Dong, E., Du, H., Gardner, L., 2020. An interactive web-based dashboard to track COVID19 in real time. Lancet Infect. Dis. 20, 533-534. https://doi.org/10.1016/S14733099(20)30120-1.

Duan, J., Yan, X., Guo, X., Cao, W., Han, W., Qi, C., Feng, J., Yang, D., Gao, G., Jin, G., 2005. A human SARS-CoV neutralizing antibody against epitope on S2 protein. Biochem. Biophys. Res. Commun. 333, 186-193. https://doi.org/10.1016/j. bbrc.2005.05.089.

Elshabrawy, H.A., Coughlin, M.M., Baker, S.C., Prabhakar, B.S., 2012. Human monoclonal antibodies against highly conserved HR1 and HR2 domains of the SARSCoV spike protein are more broadly neutralizing. PLoS One 7, e50366. https://doi. org/10.1371/journal.pone.0050366.

EUROIMMUN, 2020. Anti-SARS-CoV-2 ELISA (IgG) Instruction for Use.

Galipeau, Y., Greig, M., Liu, G., Driedger, M., Langlois, M.-A., 2020. Humoral responses and serological assays in SARS-CoV-2 infections. Front. Immunol. 11, 3382. https:// doi.org/10.3389/fimmu.2020.610688.

Gremmels, H., Winkel, B.M.F., Schuurman, R., Rosingh, A., Rigter, N.A.M., Rodriguez, O., Ubijaan, J., Wensing, A.M.J., Bonten, M.J.M., Hofstra, L.M., 2020. Real-life validation of the PanbioTM COVID-19 antigen rapid test (Abbott) in community-dwelling subjects with symptoms of potential SARS-CoV-2 infection. EClinicalMedicine. https://doi.org/10.1016/j.eclinm.2020.100677, 2020.10.16.20214189. 
Gui, M., Song, W., Zhou, H., Xu, J., Chen, S., Xiang, Y., Wang, X., 2017. Cryo-electron microscopy structures of the SARS-CoV spike glycoprotein reveal a prerequisite conformational state for receptor binding. Cell Res. 27, 119-129. https://doi.org/ 10.1038/cr.2016.152.

Guo, L., Ren, L., Yang, S., Xiao, M., Chang, D., Yang, F., dela Cruz, C.S., Wang, Y., Wu, C., Xiao, Y., Zhang, L., Han, L., Dang, S., Xu, Y., Yang, Q.W., Xu, S.Y., Zhu, H.D., Xu, Y. C., Jin, Q., Sharma, L., Wang, L., Wang, J., 2020. Profiling early humoral response to diagnose novel coronavirus disease (COVID-19). Clin. Infect. Dis. 71, 778-785. https://doi.org/10.1093/cid/ciaa310.

Hoffmann, M., Kleine-Weber, H., Schroeder, S., Krüger, N., Herrler, T., Erichsen, S., Schiergens, T.S., Herrler, G., Wu, N.H., Nitsche, A., Müller, M.A., Drosten, C., Pöhlmann, S., 2020. SARS-CoV-2 cell entry depends on ACE2 and TMPRSS2 and is blocked by a clinically proven protease inhibitor. Cell 181 (271-280), e8. https:// doi.org/10.1016/j.cell.2020.02.052.

Hsieh, C.L., Goldsmith, J.A., Schaub, J.M., DiVenere, A.M., Kuo, H.C., Javanmardi, K., Le, K.C., Wrapp, D., Lee, A.G., Liu, Y., Chou, C.W., Byrne, P.O., Hjorth, C.K., Johnson, Nv., Ludes-Meyers, J., Nguyen, A.W., Park, J., Wang, N., Amengor, D., Lavinder, J.J., Ippolito, G.C., Maynard, J.A., Finkelstein, I.J., McLellan, J.S., 2020. Structure-based design of prefusion-stabilized SARS-CoV-2 spikes. Science 369, 1501-1505. https://doi.org/10.1126/SCIENCE.ABD0826.

Huang, Y., Yang, C., Xu, feng, X., Xu, W., Liu, wen, S., 2020. Structural and functional properties of SARS-CoV-2 spike protein: potential antivirus drug development for COVID-19. Acta Pharmacol. Sin. 41, 1141-1149. https://doi.org/10.1038/s41401 020-0485-4.

ICMR, 2020. Advisory on Use of Rapid Antigen Detection Test for COVID-19.

Jiang, S., Hillyer, C., Du, L., 2020. Neutralizing antibodies against SARS-CoV-2 and other human coronaviruses. Trends Immunol. 41, 355-359. https://doi.org/10.1016/j. it.2020.03.007.

Katz, A.P., Civantos, F.J., Sargi, Z., Leibowitz, J.M., Nicolli, E.A., Weed, D., Moskovitz, A. E., Civantos, A.M., Andrews, D.M., Martinez, O., Thomas, G.R., 2020. False-positive reverse transcriptase polymerase chain reaction screening for SARS-CoV-2 in the setting of urgent head and neck surgery and otolaryngologic emergencies during the pandemic: clinical implications. Head Neck 42, 1621-1628. https://doi.org/ 10.1002/hed.26317.

Klumpp-Thomas, C., Kalish, H., Drew, M., Hunsberger, S., Snead, K., Fay, M.P., Mehalko, J., Shunmugavel, A., Wall, V., Frank, P., Denson, J.-P., Hong, M., Gulten, G., Messing, S., Hicks, J., Michael, S., Gillette, W., Hall, M.D., Memoli, M.J., Esposito, D., Sadtler, K., 2021. Standardization of ELISA protocols for serosurveys of the SARS-CoV-2 pandemic using clinical and at-home blood sampling. Nat. Commun. 12, 113. https://doi.org/10.1038/s41467-020-20383-x.

Laing, E.D., Epsi, N.J., Richard, S.A., Samuels, E.C., Wang, W., Vassell, R., Ewing, D.F., Herrup, R., Sterling, S.L., Lindholm, D.A., Millar, E.v, Maves, R.C., Larson, D.T., Colombo, R.E., Chi, S., Madar, C., Lalani, T., Ganesan, A., Fries, A., Colombo, C.J., Mende, K., Simons, M.P., Schully, K.L., Weiss, C.D., Tribble, D.R., Agan, B.K., Pollett, S.D., Broder, C.C., Burgess, T.H., 2021. SARS-CoV-2 antibodies remain detectable 12 months after infection and antibody magnitude is associated with age and COVID-19 severity. medRxiv. https://doi.org/10.1101/2021.04.27.21256207.

Liu, W., Liu, L., Kou, G., Zheng, Y., Ding, Y., Ni, W., Wang, Q., Tan, L., Wu, W., Tang, S. Xiong, Z., Zheng, S., 2020. Evaluation of nucleocapsid and spike protein-based enzyme-linked immunosorbent assays for detecting antibodies against SARS-CoV-2. J. Clin. Microbiol. 58 https://doi.org/10.1128/JCM.00461-20 e00461-20.

Long, Q.X., Tang, X.J., Shi, Q.L., Li, Q., Deng, H.J., Yuan, J., Hu, J.L., Xu, W., Zhang, Y., Lv, F.J., Su, K., Zhang, F., Gong, J., Wu, B., Liu, X.M., Li, J.J., Qiu, J.F., Chen, J., Huang, A.L., 2020. Clinical and immunological assessment of asymptomatic SARSCoV-2 infections. Nat. Med. 26, 1200-1204. https://doi.org/10.1038/s41591-0200965-6.

Mathuria, J.P., Yadav, R., Rajkumar, 2020. Laboratory diagnosis of SARS-CoV-2 - A review of current methods. J. Infect. Public Health 13, 901-905. https://doi.org/ 10.1016/j.jiph.2020.06.005.

Milani, G.P., Dioni, L., Favero, C., Cantone, L., Macchi, C., Delbue, S., Bonzini, M., Montomoli, E., Bollati, V., Albetti, B., Bandi, C., Bellini, T., Buscaglia, M., Cantarella, C., Carugno, M., Casartelli, S., D’Alessandro, S., de Chiara, F., Eberini, I. Ferrari, L., Ferraroni, M., Galastri, L., Galli, C., Hoxha, M., Iodice, S., la Vecchia, C., Manenti, A., Manini, I., Marchi, S., Mariani, J., Pariani, E., Pesatori, A.C., Rota, F., Ruscica, M., Schioppo, T., Tarantini, L., Trombetta, C.M., Vicenzi, M., Zanchetta, G., 2020. Serological follow-up of SARS-CoV-2 asymptomatic subjects. Sci. Rep. 10, 20048. https://doi.org/10.1038/s41598-020-77125-8.

Montesinos, I., Gruson, D., Kabamba, B., Dahma, H., van den Wijngaert, S., Reza, S., Carbone, V., Vandenberg, O., Gulbis, B., Wolff, F., Rodriguez-Villalobos, H., 2020. Evaluation of two automated and three rapid lateral flow immunoassays for the detection of anti-SARS-CoV-2 antibodies. J. Clin. Virol. 128, 104413 https://doi.org/ 10.1016/j.jcv.2020.104413.

Oved, K., Olmer, L., Shemer-Avni, Y., Wolf, T., Supino-Rosin, L., Prajgrod, G., Shenhar, Y., Payorsky, I., Cohen, Y., Kohn, Y., Indenbaum, V., Lazar, R., Geylis, V., Oikawa, M.T., Shinar, E., Stoyanov, E., Keinan-Boker, L., Bassal, R., Reicher, S., Yishai, R., Bar-Chaim, A., Doolman, R., Reiter, Y., Mendelson, E., Livneh, Z., Freedman, L.S., Lustig, Y., 2020. Multi-center nationwide comparison of seven serology assays reveals a SARS-CoV-2 non-responding seronegative subpopulation. EClinicalMedicine 29-30, 100651. https://doi.org/10.1016/j.eclinm.2020.100651.
Premkumar, L., Segovia-Chumbez, B., Jadi, R., Martinez, D.R., Raut, R., Markmann, A.J., Cornaby, C., Bartelt, L., Weiss, S., Park, Y., Edwards, C.E., Weimer, E., Scherer, E.M., Rouphael, N., Edupuganti, S., Weiskopf, D., Tse, Lv., Hou, Y.J., Margolis, D., Sette, A., Collins, M.H., Schmitz, J., Baric, R.S., de Silva, A.M., 2020. The receptorbinding domain of the viral spike protein is an immunodominant and highly specific target of antibodies in SARS-CoV-2 patients. Sci. Immunol. 5, eabc8413 https://doi. org/10.1126/SCIIMMUNOL.ABC8413.

Scohy, A., Anantharajah, A., Bodéus, M., Kabamba-Mukadi, B., Verroken, A., RodriguezVillalobos, H., 2020. Low performance of rapid antigen detection test as frontline testing for COVID-19 diagnosis. J. Clin. Virol. 129, 104455 https://doi.org/10.1016/ j.jcv.2020.104455.

Sethuraman, N., Jeremiah, S.S., Ryo, A., 2020. Interpreting diagnostic tests for SARSCoV-2. JAMA 323, 2249-2251. https://doi.org/10.1001/jama.2020.8259.

Shang, J., Wan, Y., Luo, C., Ye, G., Geng, Q., Auerbach, A., Li, F., 2020a. Cell entry mechanisms of SARS-CoV-2. Proc. Natl. Acad. Sci. U.S.A. 117 https://doi.org/ 10.1073/pnas. 2003138117, 11727 LP-11734.

Shang, J., Ye, G., Shi, K., Wan, Y., Luo, C., Aihara, H., Geng, Q., Auerbach, A., Li, F., $2020 \mathrm{~b}$. Structural basis of receptor recognition by SARS-CoV-2. Nature 581, 221-224. https://doi.org/10.1038/s41586-020-2179-y.

Staines, H.M., Kirwan, D.E., Clark, D.J., Adams, E.R., Augustin, Y., Byrne, R.L., Cocozza, M., Cubas-Atienzar, A.I., Cuevas, L.E., Cusinato, M., Davies, B.M.O., Davis, M., Davis, P., Duvoix, A., Eckersley, N.M., Forton, D., Fraser, A.J., Garrod, G., Hadcocks, L., Hu, Q., Johnson, M., Kay, G.A., Klekotko, K., Lewis, Z., Macallan, D.C., Mensah-Kane, J., Menzies, S., Monahan, I., Moore, C.M., Nebe-Von-Caron, G., Owen, S.I., Sainter, C., Sall, A.A., Schouten, J., Williams, C., Wilkins, J., Woolston, K., Fitchett, J.R.A., Krishna, S., Planche, T., 2020. Dynamics of IgG seroconversion and pathophysiology of COVID-19 infections. medRxiv. https://doi. org/10.1101/2020.06.07.20124636, 2020.06.07.20124636.

Suthar, M.S., Zimmerman, M.G., Kauffman, R.C., Mantus, G., Linderman, S.L., Hudson, W.H., Vanderheiden, A., Nyhoff, L., Davis, C.W., Adekunle, O., Affer, M., Sherman, M., Reynolds, S., Verkerke, H.P., Alter, D.N., Guarner, J., Bryksin, J., Horwath, M.C., Arthur, C.M., Saakadze, N., Smith, G.H., Edupuganti, S., Scherer, E. M., Hellmeister, K., Cheng, A., Morales, J.A., Neish, A.S., Stowell, S.R., Frank, F., Ortlund, E., Anderson, E.J., Menachery, V.D., Rouphael, N., Mehta, A.K. Stephens, D.S., Ahmed, R., Roback, J.D., Wrammert, J., 2020. Rapid generation of neutralizing antibody responses in COVID-19 patients. Cell Reports Medicine 1, 100040. https://doi.org/10.1016/j.xcrm.2020.100040.

To, K.K.W., Tsang, O.T.Y., Leung, W.S., Tam, A.R., Wu, T.C., Lung, D.C., Yip, C.C.Y., Cai, J.P., Chan, J.M.C., Chik, T.S.H., Lau, D.P.L., Choi, C.Y.C., Chen, L.L., Chan, W. M., Chan, K.H., Ip, J.D., Ng, A.C.K., Poon, R.W.S., Luo, C.T., Cheng, V.C.C., Chan, J. F.W., Hung, I.F.N., Chen, Z., Chen, H., Yuen, K.Y., 2020. Temporal profiles of viral load in posterior oropharyngeal saliva samples and serum antibody responses during infection by SARS-CoV-2: an observational cohort study. Lancet Infect. Dis. 20, 565-574. https://doi.org/10.1016/S1473-3099(20)30196-1.

van Elslande, J., Houben, E., Depypere, M., Brackenier, A., Desmet, S., André, E., van Ranst, M., Lagrou, K., Vermeersch, P., 2020. Diagnostic performance of seven rapid IgG/IgM antibody tests and the Euroimmun IgA/IgG ELISA in COVID-19 patients. Clin. Microbiol. Infect. 26, 1082-1087. https://doi.org/10.1016/j.cmi.2020.05.023.

Wajnberg, A., Amanat, F., Firpo, A., Altman, D.R., Bailey, M.J., Mansour, M., McMahon, M., Meade, P., Mendu, D.R., Muellers, K., Stadlbauer, D., Stone, K., Strohmeier, S., Simon, V., Aberg, J., Reich, D.L., Krammer, F., Cordon-Cardo, C., 2020. Robust neutralizing antibodies to SARS-CoV-2 infection persist for months. Science 370, 1227-1230. https://doi.org/10.1126/science.abd7728.

Walls, A.C., Park, Y.J., Tortorici, M.A., Wall, A., McGuire, A.T., Veesler, D., 2020. Structure, function, and Antigenicity of the SARS-CoV-2 spike glycoprotein. Cell 181 (281-292), e6. https://doi.org/10.1016/j.cell.2020.02.058.

Wölfel, R., Corman, V.M., Guggemos, W., Seilmaier, M., Zange, S., Müller, M.A., Niemeyer, D., Jones, T.C., Vollmar, P., Rothe, C., Hoelscher, M., Bleicker, T., Brünink, S., Schneider, J., Ehmann, R., Zwirglmaier, K., Drosten, C., Wendtner, C., 2020. Virological assessment of hospitalized patients with COVID-2019. Nature 581, 465-469. https://doi.org/10.1038/s41586-020-2196-x.

Xia, S., Zhu, Y., Liu, M., Lan, Q., Xu, W., Wu, Y., Ying, T., Liu, S., Shi, Z., Jiang, S., Lu, L., 2020. Fusion mechanism of 2019-nCoV and fusion inhibitors targeting HR1 domain in spike protein. Cell. Mol. Immunol. 17, 765-767. https://doi.org/10.1038/s41423020-0374-2.

Yamaoka, Y., Jeremiah, S.S., Miyakawa, K., Saji, R., Nishii, M., Takeuchi, I., Ryo, A., 2020. Whole nucleocapsid protein of severe acute respiratory syndrome coronavirus 2 may cause false-positive results in serological assays. Clin. Infect. Dis. https://doi. org/10.1093/cid/ciaa637.

Yuan, M., Wu, N.C., Zhu, X., Lee, C.C.D., So, R.T.Y., Lv, H., Mok, C.K.P., Wilson, I.A., 2020. A highly conserved cryptic epitope in the receptor binding domains of SARSCoV-2 and SARS-CoV. Science 368, 630-633. https://doi.org/10.1126/science. abb7269.

Zhao, J., Yuan, Q., Wang, H., Liu, W., Liao, X., Su, Y., Wang, X., Yuan, J., Li, T., Li, J., Qian, S., Hong, C., Wang, F., Liu, Y., Wang, Z., He, Q., Li, Z., He, B., Zhang, T., Fu, Y., Ge, S., Liu, L., Zhang, J., Xia, N., Zhang, Z., 2020. Antibody responses to SARS-CoV-2 in patients with novel coronavirus disease 2019. Clin. Infect. Dis. 71, 2027-2034. https://doi.org/10.1093/cid/ciaa344. 